\title{
Ethanol production by Mucor indicus using the fungal autolysate as a nutrient supplement
}

\author{
Reihaneh Asachi $^{1, *}$, Keikhosro Karimi ${ }^{1}$, Mohammad J. Taherzadeh ${ }^{2}$ \\ ${ }^{1}$ Department of Chemical Engineering, Isfahan University of Technology, Isfahan, 84156-83111, Iran \\ ${ }^{2}$ School of Engineering, University of Borås, SE-501 90 Borås, Sweden \\ *Corresponding author. Tel: +983113915623, Fax:+983113912677,E-mail: asachi@iut.ac.ir
}

\begin{abstract}
To develop a cost-effective fermentation medium, fungal extract (FE) of Mucor indicus biomass, which is a by-product of fermentation processes, was evaluated as a nutrient source for ethanol production by the fungus. Autolysis as a natural process of self-digestion of fungal cells was used to release the nutrients in surrounding medium leading to the production of the FE. Glucose consumption and ethanol production were followed using several media made with different concentrations of FE as nutrient supplementation replacing either yeast extract (YE) or whole nutrient. According to the results, $5 \mathrm{~g} / \mathrm{L} \mathrm{YE}$ could be successfully replaced with $5 \mathrm{~g} / \mathrm{L} \mathrm{FE}$, resulting in higher ethanol yield $(0.46 \mathrm{~g} / \mathrm{g})$ and productivity $(0.69 \mathrm{~g} / \mathrm{L} . \mathrm{h})$. Yield of glycerol production, the major byproduct of fermentation, was also increased by supplementation of the FE.
\end{abstract}

Keywords: Bioethanol; Fungal extract; Autolysis; Mucor indicus.

\section{Introduction}

Amongst all liquid biofuels, bioethanol is widely recognized these days as a promising renewable and environmentally friendly source of energy. It is an alternative fuel with the recognition that the global crude oil reserve is finite, and its depletion is occurring much faster than previously predicted [1]. Recently, saprophytic zygomycetes strain Mucor indicus (formerly $M$. rouxii) has been identified as an ethanol-producing organism, capable to grow aerobically or anaerobically on a number of different carbon sources including hexoses and pentoses with yield and productivity in the same order as Saccharomyces cerevisiae [2]. Furthermore, the interest in the potential utilization of fungal biomass zygomycetes as a valuable product is increasing due to the structural composition of cell walls [3]. Ethanol production by fermentation of natural feedstocks usually requires the use of complex growth supplements, such as yeast extract (YE) [2, 4]. The high cost of YE and other commercial nutrients is a limitation to its application in industrial processes, including the fermentation of biomass to ethanol. Thus, it is desirable to develop media that are likely to perform well in conditions that are representative in microbial fermentation. Several studies have concentrated on the use of yeast autolysate as effective nutrients in wheat fermentations and ethanol production [5, 6]. Fungal biomass as a by-product of fungal fermentations can be used as a source of nutrients for microbial fermentations. This can be achieved by disintegration and releasing materials hydrolyzed in-to assimilable monomers to produce a fungal autolysate as a nutrient-rich solution containing such as amino-acids, peptides, phosphorus and carbohydrates. Cell autolysis as an economical method is the natural degradation process, which starts after the exhaustion of major nutrients and reserves [7]. The objective of the present study was to develop a low-cost and suitable fermentation medium based on the utilization of filamentous fungus biomass, $M$. indicus, as a nutrient source for production of ethanol with the same fungal strain.

\section{Materials and Methods}

\subsection{Microorganism strain and media}

The fungus $M$. indicus 22424 CCUG (Culture Collection University of Göteborg, Sweden) was used in all experiments. The fungus was cultivated on agar slants containing $(\mathrm{g} / \mathrm{L})$ : 
glucose monohydrate, 40; peptone, 10 ; and agar 20 at $\mathrm{pH} 5.5 \pm 0.1$ and $32 \pm 0.5^{\circ} \mathrm{C}$ for 5 days, where the fungus grew to form a cotton-like mycelium and spores. The agar slants were stored at $4^{\circ} \mathrm{C}$ until use.

\subsection{Fungal spore germination}

The batch cultivations were carried out in 500-ml cotton-plugged conical flasks with $300 \mathrm{ml}$ working volume containing glucose monohydrate (40 g/L), supplemented with (per liter): $5 \mathrm{~g}$

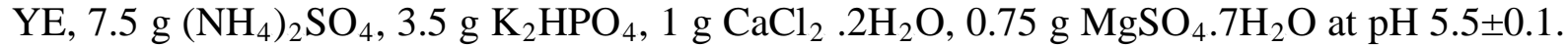
The flasks were incubated at $32 \pm 0.5^{\circ} \mathrm{C}$ and $180 \mathrm{rpm}$ for $30 \mathrm{~h}$, which provided initial biomass for further fungal autolysis.

\subsection{Fungal autolysis}

The produced biomass (fungal cells) from the fungal germination were recovered and separated from the liquid broth by filtration under aseptic conditions and washed at least three times with sterile distilled water to remove any residual nutrients. The clean solids were then re-suspended in sterile distilled water to achieve a concentration of $50 \mathrm{~g} / \mathrm{L}$ fungal biomass. The fungal suspensions were then placed in $250 \mathrm{ml}$ glass vessels immersed in a temperaturecontrolled shaking water bath. The initial $\mathrm{pH}$ was adjusted to $5.2 \pm 0.1$ using either $10 \%$ sulfuric acid or $1 \mathrm{~N}$ sodium hydroxide. The autolysis was carried out at $55 \pm 1^{\circ} \mathrm{C}$ and $120 \mathrm{rpm}$ for $72 \mathrm{~h}$. After autolysis, the suspension was centrifuged for $15 \mathrm{~min}$ at $4^{\circ} \mathrm{C}$ and $4500 \mathrm{rpm}$, and the supernatant was designated as autolysate of fungal cells. The solubilized cell constituents in autolysate of fungal cells resulting from the autolysis were referred to as "FE".

\subsection{Ethanol production}

The fermentation experiments were carried out anaerobically in $120 \mathrm{ml}$ glass bottles with 50 $\mathrm{ml}$ working volume, containing $40 \mathrm{~g} / \mathrm{L}$ glucose monohydrate and different media supplementation (Table 1) in $50 \mathrm{mM}$ sodium citrate buffer with $\mathrm{pH} 5.5 \pm 0.1$. The media were sterilized by autoclaving at $121^{\circ} \mathrm{C}$ for $20 \mathrm{~min}$, and then inoculated with $1.0 \mathrm{ml}$ of a suspension containing $4.5( \pm 0.5) \times 10^{5}$ spores of $M$. indicus. The fully nutrient medium containing YE (5 $\mathrm{g} / \mathrm{L})$ supplemented with mineral salts $(\mathrm{g} / \mathrm{L}):\left(\mathrm{NH}_{4}\right)_{2} \mathrm{SO}_{4}, 7.5, \mathrm{~K}_{2} \mathrm{HPO}_{4}, 3.5, \mathrm{CaCl}_{2} .2 \mathrm{H}_{2} \mathrm{O}, 1$, $\mathrm{MgSO}_{4} .7 \mathrm{H}_{2} \mathrm{O}, 0.75$. Table 1 shows the type of supplementation corresponding to the various media assayed. All fermentations were performed in a shaking incubator at $32 \pm 0.5^{\circ} \mathrm{C}$ with the agitation speed of $180 \mathrm{rpm}$ for $72 \mathrm{~h}$. The fermentation samples were stored at $-20^{\circ} \mathrm{C}$ before metabolite analysis.

\subsection{Analytical methods}

For determination of the amount of materials released from the cells into the surrounding liquid phase during autolysis (FE), $10 \mathrm{ml}$ of autolysate of fungal cells after autolysis process was separated and dried in an oven at $55 \pm 1^{\circ} \mathrm{C}$ until constant weight was achieved. The liquid samples from fermentations were analyzed by high performance liquid chromatography (HPLC), which was equipped with UV/vis and RI detectors (Jasco International Co., Tokyo, Japan). Glucose, ethanol, glycerol were analyzed on an Aminex HPX-87H column (Bio-Rad, Richmond, CA, USA) at $60^{\circ} \mathrm{C}$ with $0.6 \mathrm{ml} / \mathrm{min}$ eluent of $5 \mathrm{mM}$ sulfuric acid. All components were detected on RI chromatograms. All experiments in this work were duplicated and the averages of two replications are presented. 


\section{Results}

\subsection{Effect of the supplementation of fungal extract on ethanol production}

$M$. indicus was produced in the fully supplemented medium containing $40 \mathrm{~g} / \mathrm{L}$ glucose monohydrate and other nutrient components, and the produced fugal cells were recovered by filtration and were subjected to fungal autolysis process. To verify the potential of FE as an alternative nutrient supplementation replacing YE, a series of experimental fermentations were performed at two concentrations ( 2.5 and $5 \mathrm{~g} / \mathrm{L}$ ) of FE (Table 1$)$.

Table 1. Results of ethanol production by M. indicus in different media.

\begin{tabular}{|c|c|c|c|c|}
\hline Nutrient Supplementation & $\begin{array}{l}\text { Maximum ethanol } \\
\text { volumetric } \\
\text { productivity }(\mathrm{g} / \mathrm{L} \mathrm{h})\end{array}$ & $\begin{array}{l}Y_{E / S}{ }^{b} \\
(g / g)\end{array}$ & $\begin{array}{l}\mathrm{Y}_{\mathrm{Gly} / \mathrm{S}}{ }^{\mathrm{C}} \\
(\mathrm{mg} / \mathrm{g})\end{array}$ & $\begin{array}{l}\text { Terminal } \\
\text { time (h) }\end{array}$ \\
\hline YE (5 g/L), mineral salts ${ }^{\mathrm{a}}$ & 0.67 & 0.45 & 47.3 & 24 \\
\hline YE $(5 \mathrm{~g} / \mathrm{L})$ & 0.37 & 0.43 & 46.4 & 48 \\
\hline FE $(2.5 \mathrm{~g} / \mathrm{L})$ & 0.34 & 0.39 & 43.3 & 72 \\
\hline FE (2.5 g/L), mineral salts & 0.53 & 0.40 & 42.0 & 36 \\
\hline $\mathrm{FE}(5 \mathrm{~g} / \mathrm{L})$ & 0.54 & 0.43 & 45.1 & 36 \\
\hline FE (5 g/L), mineral salts & 0.69 & 0.46 & 49.0 & 24 \\
\hline
\end{tabular}

To establish a basis for comparison, a fermentation run was carried out in a fully supplemented medium (YE (5 g/L) and mineral salts). The results showed that, glucose was rapidly consumed and mainly converted to ethanol (Fig. 1a and b), reaching a maximum yield of $0.45 \mathrm{~g} /$ (g glucose) and a volumetric productivity of $0.67 \mathrm{~g} / \mathrm{L}$ h in less than $24 \mathrm{~h}$ cultivation under anaerobic conditions. Glycerol was the most important byproduct of the fermentation with maximum yield of $47.3 \mathrm{mg} / \mathrm{g}$ glucose (Table 1 ). As can be seen from Table $1, M$. indicus gave the ethanol yield of $0.43 \mathrm{~g} / \mathrm{g}$ and low productivity with the supplementation of only 5 $\mathrm{g} / \mathrm{L}$ YE (Table 1). A preliminary experiment was carried out using $2.5 \mathrm{~g} / \mathrm{L}$ of $\mathrm{FE}$ as unique supplementation (Table 1). As a result, the low glucose consumption indicated the existence of nutrient limitation in the medium and the maximum ethanol concentration was reached after a relatively long reaction time (about $72 \mathrm{~h}$ ). However, the experiment with supplementation of $2.5 \mathrm{~g} / \mathrm{L}$ FE gave a poor performance in ethanol production because of nutrient limitation in fermentation media relative to $\mathrm{YE}$ or whole nutrient supplementations. 

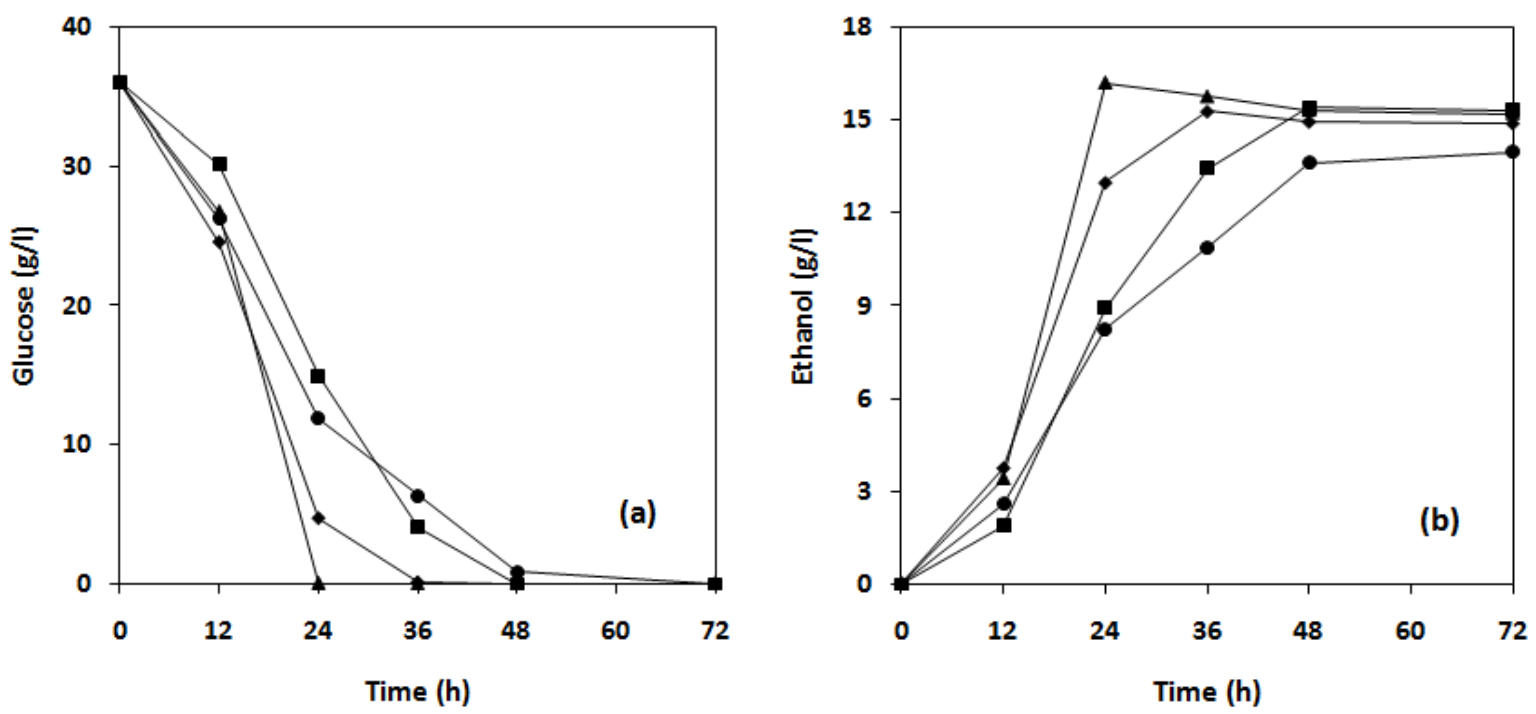

Fig.1. Effect of the supplementation of fungal extract on glucose assimilation (a) and e thanol production (b). The symbols represent of supplementation of $Y E(5 \mathrm{~g} / \mathrm{L})(\mathbf{-}) ; Y E(5 \mathrm{~g} / \mathrm{L})$ with mineral

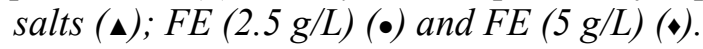

In this direction, an additional experiment performed in order to increase the nutrient concentration with $5 \mathrm{~g} / \mathrm{L}$ FE of $M$. indicus as unique supplementation (Table 1). Compared with $5 \mathrm{~g} / \mathrm{L} \mathrm{YE,} 5 \mathrm{~g} / \mathrm{L}$ FE resulted in a higher ethanol yield with a maximum of $0.43 \mathrm{~g} / \mathrm{g}$. However, the low glucose consumption indicated the existence of nutrient limitation in the medium. As a result, the maximum yield and productivity of ethanol in this medium was still lower than the fully supplemented medium (Table 1).

\subsection{Evaluation of fungal extract for media supplementation replacing yeast extract}

The possibility of supplementing of FE $(2.5 \mathrm{~g} / \mathrm{L})$ in the fermentation media with combination of mineral salts (Table 1) was assessed in an additional experiment to overcome nutrient limitation. According to Table 1, addition of the mineral salts provided a gradual increase in ethanol yield and volumetric productivity in comparison with addition of only $2.5 \mathrm{~g} / \mathrm{L} \mathrm{FE}$. However, it was comparatively low due to result obtained in a fully supplemented medium. Considering that a deficit in mineral salts with $5 \mathrm{~g} / \mathrm{L}$ FE supplementation could be partially responsible for the prolonged fermentation time, additional experiment was prepared by adding the mineral salts presented in the full nutrient medium. As a result of this modification, the bioconversion to ethanol was further improved and showed results closely related to the ones observed for the fully supplemented medium (Fig. 2a and b), with a maximum ethanol yield and productivity of $0.46 \mathrm{~g} / \mathrm{g}$ and $0.69 \mathrm{~g} / \mathrm{L} \mathrm{h}$ in less than $24 \mathrm{~h}$, respectively. The maximum glycerol yield of $0.49 \mathrm{mg} / \mathrm{g}$ was achieved at this condition. It came, therefore, to the conclusion that autolysis of $M$. indicus biomass as a valuable by product from ethanol fermentation could be used as a microbial nutrient source for further fermentation with supplementation of $5 \mathrm{~g} / \mathrm{L}$ FE replacing $5 \mathrm{~g} / \mathrm{L} \mathrm{YE.}$ 

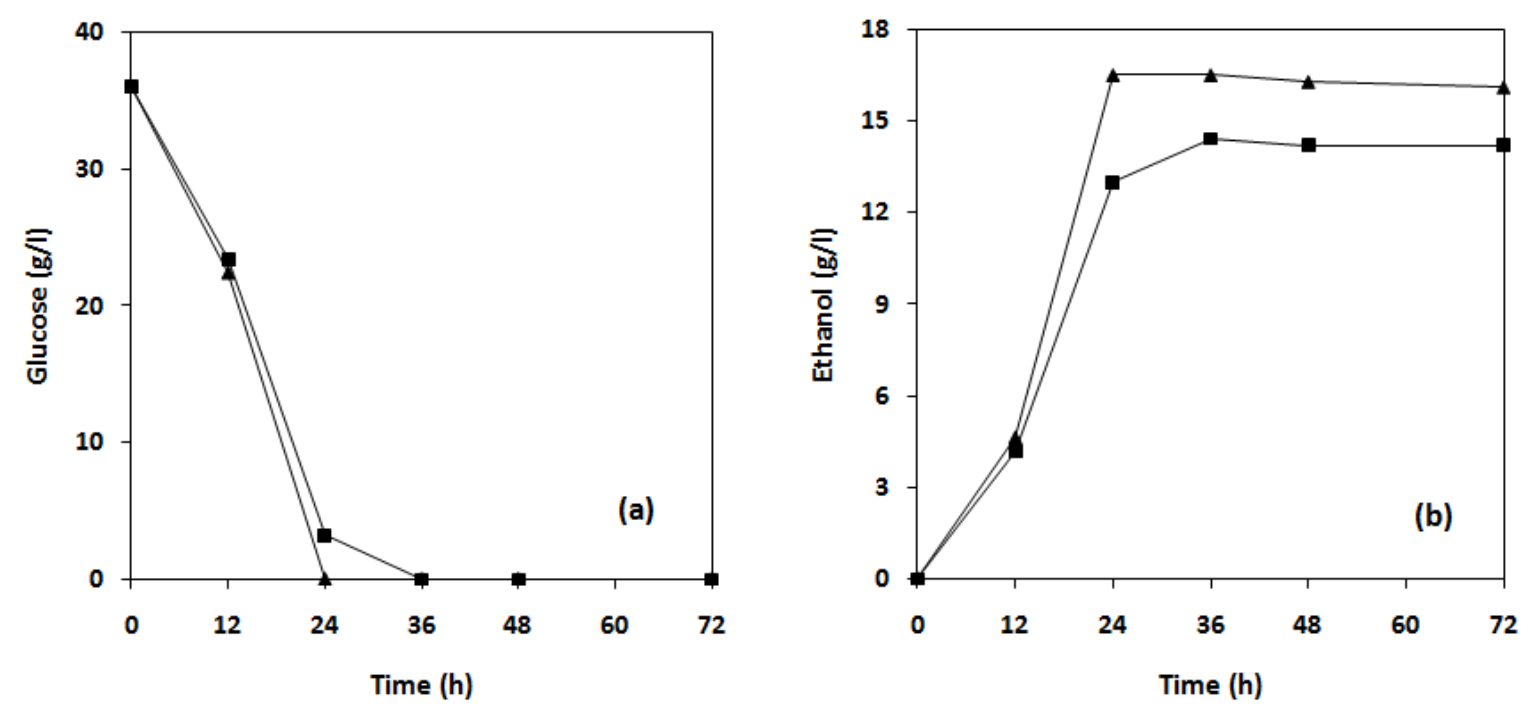

Fig.2. Effect of the supplementation of fungal extract with combination of mineral salts on glucose assimilation (a) and ethanol production (b). The symbols represent of supplementation of FE $(2.5 \mathrm{~g} / \mathrm{L})$

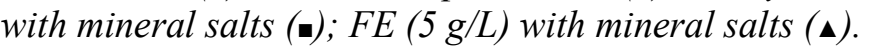

\section{Discussion}

The main purpose of the current work was the fermentative production of ethanol by the filamentous fungus, $M$. indicus, using a fungal autolysate as a low-cost complex nutrient solution. $M$. indicus is a fungus that has recently been identified as a candidate for industrial production of ethanol $[2,4]$. Considering the similarity of chemical components between $M$. indicus and yeasts, it might be assumed that the fungal extract might be a feasible alternative to yeast extract as a nutrient source for fermentation media. Thus, the fungal cells of $M$. indicus, as a by-product of fermentation processes, were then subjected to autolysis to produce nutrient supplements for the following fermentations by similar fungus $M$. indicus. Therefore, the autolysis of the fungal cells biomass produced during fermentation may be considered as a suitable replacement for YE. Thus, the natural enzymatic process of fungal autolysis under oxygen starvation conditions was used in order to disrupt $M$. indicus cells and release various nutrients into the surrounding liquid. On the other hand, this process could be applied as an effective approach to nutrient regeneration/ production due to its simplicity [7]. In this study, autolysate of fungal cells, referred to as FE resulted in high performance in ethanol production. Media containing FE (5 g/L) replacing YE as nutrient source led to highyield and high-volumetric productivity of ethanol. In addition high-yield of glycerol was obtained in FE concentration (5 g/L) relative to fully supplemented medium. This demonstrates clearly that the FE of $M$. indicus contains sufficient essential nutrients for the ethanol fermentation.

\section{Conclusion}

The biomass of $M$. indicus can be used as a nutrient source for ethanol production by this fungus. Autolysate of the fungal cells could successfully replace the major nutrients which are necessary for the fermentation. 


\section{References}

[1] A. Demirbas, Progress and recent trends in biofuels, Progress in energy and combustion science 33, 2007, pp. 1-18.

[2] A. Sues, et al., Ethanol production from hexoses, pentoses, and dilute-acid hydrolyzate by Mucor indicus, Fems Yeast Research 5, 2005, pp. 669-676.

[3] S. Chatterjee, et al., Chitosan from Mucor rouxii: production and physico-chemical characterization, Process Biochemistry 40, 2005, pp. 395-400.

[4] K. Karimi, et al., Mucor indicus as a biofilter and fermenting organism in continuous ethanol production from lignocellulosic hydrolyzate, Biochemical Engineering Journal 39, 2008, pp. 383-388.

[5] S. W. York and L. O. Ingram, Ethanol production by recombinant Escherichia coli KO11 using crude yeast autolysate as a nutrient supplement, Biotechnology Letters 18, 1996, pp. 683-688.

[6] A. Jones and W. Ingledew, Fuel alcohol production: appraisal of nitrogenous yeast foods for very high gravity wheat mash fermentation, Process Biochemistry 29, 1994, pp. 483488,.

[7] A. A. Koutinas, et al., Development of a process for the production of nutrient supplements for fermentations based on fungal autolysis, Enzyme and Microbial Technology 36, 2005, pp. 629-638. 